\title{
Development of Course Learning Devices Integrated (SD Mathemathics Learning) MitApp-Based Local Wisdom
}

\author{
$1^{\text {st }}$ Elvi Mailani ${ }^{1}, 2^{\text {nd }}$ Daitin Tarigan, $3^{\text {rd }}$ Akden Simanihuruk, $4^{\text {th }}$ Suyit Ratno \\ \{elvimailani@unimed.ac.id ${ }^{1}$ \} \\ Elementary School Teacher Education Program, Universitas Negeri Medan, Indonesia ${ }^{1}$
}

\begin{abstract}
This research is intended to develop the material for Unimed PGSD (Elementary School Teacher Education) math students in Elementary School. The elementary school math course is a new college education for Indonesian PGSD students in accordance with the policy of the minister of education associated with the free college. The development of the teach material is felt necessary because of the Study materials for the mathematics study in elementary school that will use by lecturer and students nothing at all. The target of this research are: (1) a resource study materials for mathematics lecturer and students at the integrated elementary school of north Sumatra local wisdom, (2) a reputable scientific publication of a journal or indexed scopus or web of science. The method of executing research uses the model van den acker: (1) initial analysis, (2) expert and teacher evaluations, (3) initial model of the teaching material (4) validation of the teaching material (5) empirical data, (6) reflection and revision.
\end{abstract}

Keywords: course learning, mathematics, MitApp, local wisdom.

\section{Introduction}

Math lessons especially in basic education nowadays are considered very difficult subjects to understand, math learning requires excellent reasoning, requires high levels of intelegence, not everyone can understand, so students are less interested in attending this lesson. The student feels that math lessons given by the teacher have been less interesting, boring, and no variation at all in his learning process. Math teachers should need to pack up a more attractive set of mathematical learning so that students do not get bored, so that students can be more seriously at learning and can easily accept and understand the math concepts being taught.

The presents above a challenge for teachers especially who teach in the primary school teacher's education department (PGSD) of Unimed education faculty. Unimed PGSD is an institution that is basically a container for educating and training for elementary school teachers, and it certainly has a great responsibility to cope with such challenges. Through college teaching activities, Unimed PGSD students are expected to gain immediate knowledge and skills especially in how to make math subjects into one subject that is beloved and of interest to the elementary school students, so that the materials that students study can easily be mastered by methods, teaching strategies done by teachers.

The new policy was launched by minister of education and culture Nadiem Makarim, through the free college program, provides some hope and refreshment for the revival of the 
studying process especially for students. Students have the opportunity to select and master the knowledge they need to enter the workforce. The free college gives the students the opportunity to pick out the text they're going to take. Learning in an free college presents challenges and opportunities for the development of creativity, capacity, personality, and students' needs, and developing self-reliance in search of and discover knowledge through field realities and dynamics such as skill requirements, real issues, social interaction, collaboration, self-management, performance demands, goals and rewards.

For the Unimed PGSD department at the launch of January 2020 by dictating the growth of the education system in the program. Hope and challenges go hand in hand as the program moves along. One of the challenges that concerns lecturers who teach in the primary school teacher's education (PGSD) is the changing of the curriculum. Changing curriculum impacts the changes and additions of several courses. Adding this course is certainly a challenge for PGSD lecturers because of the very limited time of the new program requires energy and critical thinking. New subjects organized not only into written schedules but also must be supported by teaching materials that give students critical thinking and exploration ability for the students. The compilation of a new curriculum must also be based upon the ideals (vision, mission and purpose) of the education program itself.

The development of the teaching material is essential because it is one of the needs to be met in the college process. One of the new courses on the independent college program in Unimed's PGSD department was a math materials at elementary school. The mathematics of elementary school education is the arts of the college which, in its curriculum demands, is not only to imbue students with abstract mathematical concepts, but more important is how to explain, teach, and understand to students how to apply these abstract mathematical materials to elementary school students. It is to be expected with these students being able and having more solid ideas, ideas, and insights how easy it is to teach the math materials to students at elementary school.

One way to do this research is to develop the teaching materials for math classes in elementary school that, to this day, there are no feedtools that will eventually be used by lecturers and students by integrating them into local wisdom in north Sumatera. Based on the background of the problems in the Indonesian era of the pandemic covid-19, researchers are interested in conducting research on a lower - class math course entitled: "development of inferior mathematical applications using the MIT app Inventor for Unimed PGSD students.

Teaching materials are a set of tools or learning tools that contain learning materials, methods, limitations, and a manner of systematically designed and attractive design in order to achieve the desired goals, namely, to achieve competence and subcompetency with all its complexity [1]. This understanding illustrates that it should be designed and written according to the learning code, that is, adjusted learning materials, compiled upon learning needs, there are assessments, and the teaching material is interesting for students to study.

Teaching is a body of information that learners must absorb through enjoyable study [2]. This suggests that in the composition of the teaching, it is expected that the student will truly feel the benefit of the material after learning it. It is a medium to achieve desires or goals that learners will achieve. Instructional materials are the audio visual materials (software/hardware) which can be used as alternative channels of communication in the teaching-learning process [3]. It is a visual and audiovisual resource that can be used as an alternative channel for communication in the learning process.

Based on the above study, the term teach material used in this study is a systematically prepared lesson material that lecturers and students use in lectures to achieve the desired goal. 
Reveals that teaching materials are systematically arranged lesson materials, which lecturers and students use in the learning process [4].

The type of teaching material is distinguished over several groupings criteria: (a) teaching material designed to learn, such as books, handouts, LKS and modules; (b) teaching material that is not designed but can be used to learn, such as clippings, newspapers, movies, advertisements or news. Koesnandar also stated that when viewed from their function, the three group of study material, reference material, and personal study material .

The development of a teaching materials must be based on a student's need sanalysis. There are a number of reasons why teaching is necessary, as follows.

- availability of materials according to curriculum requirements, which means that learning materials that are developed must correspond to the curriculum;

- target characteristics, meaning that the teaching material developed can be adjusted to students' characteristics as target, those characteristics include the social environment, culture, geography, and stages of student development;

- development of teaching materials must be able to answer or solve problem or difficulty on study.

Thus, the development of the teaching materials in college will need to take note of the characteristics of the students and according to the curriculum, which requires more student participation and activation in the course. The development of a student activity sheet is one of the possible teaching alternatives for students to master a certain competence, as student activity sheet can help students supplement information about the material learned through a systematic study activity.

As with widodo and the temporal, the materials have the following characteristics [5].

- self instructional, which means the teaching material can be studied by the students personally because it is prepared for that purpose.

- $\quad$ self explanatory power, which is the teaching material, is able to explain itself by using simple language, and complical.

- $\quad$ self paced learning, that is, students can learn the teaching material at pace they would like to go without having to wait for other students who are slower or feel behind.

- $\quad$ self - containned of the teaching material is so complete that the student does not need to be dependent on other teaching unless it is intended to enrich and deeper his knowledge.

- individualized learning materials, which are taught materials designed according to the capabilities and characteristics of the student learning them.

- flexible and mobile learning materials, which students can learn at any time, anywhere, in silence or in motion.

- communicative and interactive learning materials, which are teaching are designed according to effective communicative principles and involves the process of interaction with students studying them.

- $\quad$ multimedia, computer based materials, multimedia design materials, including computer scampering optimally when students have access to them.

- tutorials by tutorials, and study groups, which are teaching materials may still need tutorial support and study groups.

Attendance of the teach material in addition to helping the student in learning is also helpful to the teacher. With the teaching materials, it will be more comfortable to develop the lesson materials. Based on the above two opinions on the characteristics of the material, researchers postulate that it should contain sufficient, varied, profound, easy to read, and according to student interests and needs. In addition, it must contain systematically and 
gradually arranged material. Materials are presented using methods and means that stimulate students to be interested in reading. Finally, the lesson must contain an evaluation tool that enables the student to be able to know the competence it has already accomplished.

MIT App Inventor are open-source web applications originally developed by Google, currently run by the Massachusetts institute of technology (MIT). App Inventor enables a newbie to do computer programming to create a software application for an android operating system. MIT App Inventor update was developed using a visual programming engine developed by Google, which is Google blocky. MIT app Inventor settlement is a joint research between MIT and Google. App allows new users to program computers to form software on an android's operating system. It involves multiple interface, like a kind of user interface for scratch and TNG starlogo, which allows users to drag and drop the subject visuals to form applications that can be run by an android device.

In developing an App Inventor, Google has conducted research related to educational computing and completed Google's online development environment. On the application there are several top components: (1) the designer components designer components consist of five parts, including palette, software, honor, media and properties, and they honor the browser with which the components are used to define the properties. (2) block editors block editors walk outside the browser and are used to make and govern ingredients of the components we choose from the designer components; (3) emulator used to run and test the established project. A visual programming framework linked to MIT programming language specifically is the implementation of an open block distributed by MIT scheller teacher education program. App Inventor 2 is equipped with full features, such as: 1) just for fun it can be a fun thing like a facility for photoediting, playing puzzles, doing crossword puzzles, or learning asa basis for reinforcing logic. It's all fun. 2) advanced app learning devices can be used as good learning tools. If we are a teacher ora teacher, we can make a teaching app a teaching tool because visualize will help students understand the material. 3) make applications of those features build prototypes, applications for personal and organizational uses, or apps for sale.

The benefits of a surgical app, among other things:

1. No need to write down no conventional program code, a visual app based visual blocks programming. There are little programmed blocks, so we just have to make them.

2. Based drag and drop, it facilitates users in designing applications. Users simply drag and drop components needed from pallete to the viewer (application screen). Then arrange an UI (user interface or view) through the properties panel.

3. Friendly user (user friendly), app level 2 is simplified and easy to use.

4. There are three direct-testing options that include usb data cables, emulators, and wireless networks. If you want to try using usb data cable, you can select usb menu. If you do not have a smartphone android there is no need to worry, since it provides an emulator to test programs virtually. The amazing thing is that we can try a program without a usb data cable, we can test the program using a wi-fi network.

The disadvantage:

1. Because it has to be connected to the Internet and it also needs to register first (to overcome it, there is a version of a offline app app, only a laptop or a computer).

2. The initial page of the application is totally blank, so we're arranging the elements ourselves to look interesting.

3. The view of creating and being present is sometimes a little different. 


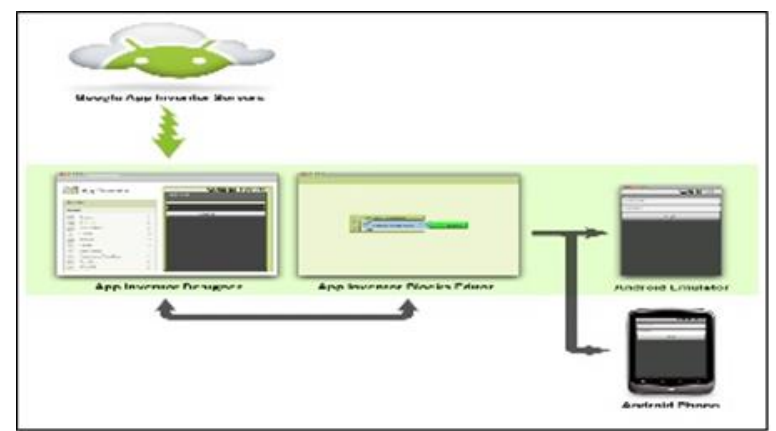

Fig. 1. MIT App Inventor Diagram.

Local wisdom is one of the key elements in a society, namely the ideal of social order. Local wisdom, in which moral teachings are found can be a guide to members of society in behavior, of what there can and cannot be, of what is good and what is bad, and what is worthy and what is not worthy to do. In other words, local wisdom can be a guidance for community members to work toward a desired value system. Local wisdom also plays an important role for communities in the face of life's problems in both social, economic, political, environmental, and other areas. In the current era of globalization and modernization, local wisdom may also play the values filtere, in which it chooses which values are positive and which ones are worth taking and which ones are not. Indonesia is a nation-rich nation of local wisdom. Local wisdom can be attained in various forms and sources, such as art, ritual, literacy, mythology, architecture, and so forth.

Local wisdom can take the form of various traditional games that have developed in communities. Traditional games that can be used to teach the process of mathematical learning: (1) using the margalla game, (2) the learning process uses the philosophy dalian na tolu, (3) the learning process uses the litun, (4) batak toba marsijontir five, (5) corsair games, (6) markadot games.

\section{Method}

The study is conducted on the faculty of education (FIP) university education in the elementary-school teacher (PGSD) proficiency of lower-grade math applications using an MIT app Inventor for elementary-school teacher (PGSD) for students to provide insights and knowledge for elementary school student math materials. This research employs methods of development research. Richey and nelson (1996) identify that developmental research (developmental research) is developmentally oriented on a product development in which the development process is described as possible and the product is eventually evaluated. Van den acker (1999) calls it an formative study where the work is performed in a cyclic process and is aimed at optifying the quality of implementation of the product in a given situation.

Researchers use the six elements found in the van den acker development model: (1) initial analysis, (2) expert and teacher evaluation, (3) the original model of teach (4) validation of visual materials (5) empirical data, (6) reflections and revision. The sequence of high-grade mathematical development materials using an MIT app Inventor application based on research model and van den acker development can be seen from the following picture: 


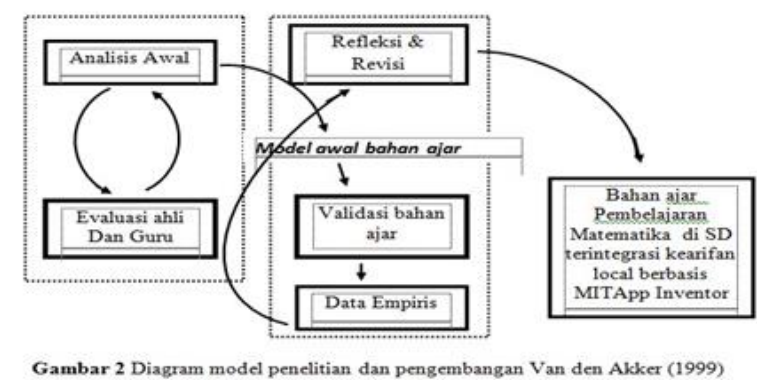

Fig. 2. Development of Course Learning Devices Integrated (SD Mathemathics Learning) MitAppBased Local Wisdom.

The research location is in the PGSD FIP UNIMED Study Program and all research activities are carried out online. The research subjects are 6th semester students of the $2020 / 2021$ academic year. The object of research is the validity, implementation, and effectiveness of the integrated teaching materials of the Sibelius 7 application developed. The stages of development in Figure 3.1 can be detailed as follows:

1. The definition stage aims to define and analyze the following: (1) need analysis of learning outcomes: art teaching materials (music), (2) analysis of the use of Sibelius 7 to optimize art (music) learning, (3) analysis of the context of cultural diversity in PGSD as a basis for art practice material, and (4) competency analysis

2. The design stage is designing teaching materials according to the definition: needs analysis, usage analysis, multi-cultural analysis, and competency analysis

3. The development stage includes: validity test, implementation test, and effectiveness test.

4. The dissemination stage is disseminated on a wider scale, both in other classes at UNIMED and at other universities.

\subsection{Stage of device development}

Initial Analysis. The initial analysis consists of several phases to do that:

\section{- Goal Analysis}

The purpose of this analysis is to establish the basic direction needed in developing lowergrade math tools using the MIT app Inventor that Unimed PGSD students will use asa provision for their future graduate and elementary school teachers. From this basic direction then compiled alternative high-grade math materials using the MIT app apps. In carrying out the goal analysis, judging from aspects of the curriculum used at the current grade school level.

- Student characteristic analysis

Student analysis is a student characteristic that covers a student's level of cognitive, ability, knowledge background, and social background of a student culture. From these analyses it will then be a framework for designing lower-class mathematical materials using the MIT app Inventor applications for lower levels to be worn by teachers and students so that lower class math materials developed according to student characteristics. 
- A teacher's need analysis

The professor's need analysis is the primary study of needs in the development of lowgrade math materials using this state-of-the-art MIT app Inventor. This analysis is based on the experience of the lecture process in which it is obvious that the teacher is attempting to explain the concept of mathematical material. In the meantime, Unimed PGSD students are also precurators of teachers, who will also be taught in elementary schools, and will also be faced with the same constraints if not equipped with good math skills.

Expert evaluation and teacher. Based on initial analysis already done, vahan taught the meteminventor lower application using the MIT app Inventor application that will be used to address the problem of elementary school mathematics. Expert and teacher assessments are performed after lower-grade math materials using the MIT app Inventor surveys are completed by researchers. An evaluation will be conducted to see if after materials from lowgrade mathematics use MIT app Inventor applications designed to match the characteristics of elementary school cranes, are harmless and can help Unimed PGSD professors and students make it easier to provide understanding of mathematical subjects, As for students whether after materials for low-grade mathematics using the MIT app Inventor can make it easier for their understanding of the materials found in lower grade math education programs.

Early model development of the yield. The first step done by researchers is to design and develop the initial model of lower-class mathematics materials using the MIT app Inventor. Early model development of low-grade mathematical materials using these MIT app Inventor must have been done by researchers according to prescribed guidelines. The developed teaching material is tailored in such a way as to some of these: (1) the teaching material can be learned on its own by the student, (2) it is able to explain itself because it uses simple language, $t$, and is sistematically composed, (3) a student can study the teaching material at pace consistent with his or her own without having to wait for other students who are slower or miss out on those faster students, (4) it is complete by itself so that students do not have to depend on other teaching materials, Unless it is intended to enrich and deepen the knowledge, and (5) the teaching materials are designed according to the ability and characteristics of the student who is studying them.

The creation of instructional validation \& validation instruments. In accordance with the research's goal for creating lower-grade mathematical materials using the MIT app advanced, and in this research, it will develop a validation instrument which is validation to measure the quality of low-grade math materials using the developed MIT app Inventor. The creation of validation instruments to assess the quality of high-grade mathematical materials using the MIT app Inventor application based on (a) inferior mathematical alignment with the low-grade curriculum (b) facilitating lower-class math applications using the MIT app Inventor advanced in providing a student's understanding of the material concepts learned, (c) appropriate language usage according to the level and character of the student (d) view of the teach

After the validation instruments have been compiled, the next activity is to validate lowergrade math materials using a state-of-the-art MIT app Inventor using the validation sheet. The validation is done by an expert and 3 people a math study teacher aimed at seeing the effectiveness, strengths, weaknesses and other things of low-grade math materials using the currently developed MIT app. The results of validation that are done will be input for the repair of low-grade mathematical materials using the MIT app apps for educational materials. 
Empirical data. Once the lower-class math materials use the MIT app Inventor application are completed validating by the validator team, then the next step is to do the doctrinal repair in accordance with the input of the validation team. The aim is to improve any available teaching material based on the results of that validation so that low-grade math materials using the developed MIT app can make it easier for Unimed PGSD students to study the material material they will be learning at a lower level of mathematics. Once low - grade math materials use the MIT app adaptive are completed, then next is the online testing of lowergrade math applications using the MIT app Inventor.

Reflections and revisions. Based on the results of tests and interviews done to students, it is possible to reflect and revise the development of low-grade math materials using the MIT app Inventor. Reflection and revision aim to correct any deficiency from low-grade math materials using the MIT app Inventor application before it was further developed and used into material on a low-grade math education course in the elementary school teacher's education course.

SD Mathemtics Learning materials using an MIT app Inventor application. The final stage of this study is developing low-grade math materials using a state-of-the-art MIT app Inventor after obtaining input from both validation activities, and based on a reflection when done online tests are done with students at the faculty of at-home primary school teachers.

\subsection{Research Instruments}

The instruments used in this study are grouped in two kinds; (1) low-grade mathematical validation instruments use the MIT app Inventor application, (2) interviews of students after the learning process use low-grade math materials using the MIT app Inventor.

\subsection{Data analysis techniques}

Data analysis is a process of organizing data sequences, organizing them into a basic pattern, category, and description unit [6]. Data analysis covers the entire activity clarifying, analyzing, applying and drawing conclusions from all the data gathered in action. The data analysis techniques used for processing the data acquired in the development of high-grade math education using a quantitative application are a quantitative description. Quantitative descriptive analysis is generated from data obtained from expert test scores, initial field tests, main field tests, and operational field tests. The data analysis techniques on the experts' validation use a likert scale with a assessment scale of 1-5. The 1-5 has an explanation, the number 1) very less, 2) less, 3) enough, 4) good and 5) excellent. Next on the worthiness data goes through the following steps of analysis:

We actually recapitulated data based on research. Changing qualitative shape assessments into quantitative uses the likert scale with the following conditions:

- Do recapitulation data base on reaserch result, change the qualitative score to be quantitative by using likert scale, base on criteria :

Table 1. Score Giving Guidance.

\begin{tabular}{cc}
\hline Qualitative data & Score \\
\hline SB (Excellent) & 5 \\
B (Good) & 4 \\
\hline
\end{tabular}




\begin{tabular}{cc}
\hline C (Enough) & 3 \\
KB (Less) & 2 \\
TB (Very Less) & 1 \\
\hline
\end{tabular}

- Counting the average score from the instrument base on this equation :

$$
\bar{X}=\frac{\sum x}{n}
$$

Information :

$\bar{X}$ : Average score

$\sum \mathrm{x}$ : sum of the score

$\mathrm{n}$ : sum of the experiment subject

\section{Results and Discussion}

The validation activity of materials on integrated mathematics studies of local wisdom in north Sumatra was developed by this researcher by teachers, headmasters and team experts from the terrain state university. The validator team validates by employing a prepared validation sheet on research for materials development taught local wisdom in north Sumatra using an MIT app Inventor application. Validation results by the validator team in general show that a draft of materials taught by local wisdom in north Sumatra using an existing MIT app Inventor is already in good category. Only a few in particular had to be revised and refurbished by the developer team. That should be done immediately, that the application of materials for integrated mathematics education local wisdom in north Sumatra using this stateof-the-art MIT app Inventor could soon be realized. Some of the input from a team of experts working on validator materials integrated mathematics studies in north Sumatra used the MIT App Inventor application of local wisdom in north Sumatra: (a) local judiciary selection used particularly the game fojusjan used on the school environment, (b) instruction clarity inan invetor MIT app Inventor is more improved to provide more ease to users. And (c) more games have been played with the diversity of tribes within the northern province of north Sumatra, so it is not focused on just any particular tribe.

The general result of validator's validation team for the development of materials integrated mathematics learning local wisdom in north Sumatra using the existing MIT app Inventor can be seen below:

1. Teaching matches the curriculum used. The development of materials taught locally integrated mathematics studies in north Sumatra using the MIT app Inventor innovations in place in accordance with the 2013 curriculum currently in use. Moreover, the depth of the mathematics materials already available is consistent with the development of children on elementary schools and students as users of materials integrated local wisdom in north Sumatra using this MIT app Inventor. The material courses presented and expounded are very accurate and by showing accuracy in applying flat, clear, easy to understand, and precise usage according to the subject. Material is expounded using raw Indonesian and according to the general guidelines of Indonesian spelling.

2. Corresponding language use to the level and character of learners. The sentence used makes possible the content of the text and refers to the correct and good English sentence code. The language used is straightforward according to the thinking abilities of learners 
and students. Examples can bring clarity from abstract concepts to more concrete. The concept is concrete, to be seen by learners around both home and school environment, and when abstract can be imagined by learners with their imagination. Messages are presented in colorful, easily understood, communicative, and encourage learners to read through. The illustration presented clarifies the material outlined. Illustration comes from a local environment in the scientific field. The grammar of the Indonesian grammar of the language used to explain a concept according to the development of learners and according to the level of emotional maturity of learners

3. Ease the use of the MIT app Inventor in giving understanding of the concepts of materials learned. The applications shown do much to help students understand the various concepts being studied. This is because the media is helping students find solutions and problem solving the various concepts being discussed in each material.

4. Local wisdom displayed. Local examples of wisdom displayed stimulate the passion and motivation of students to learn so that they can be motivated to play while studying. An example of local wisdom is one often found ina student's everyday life.

5. Illustrations of pictures found in the MIT app Inventor workshops are presented as compelling, clear and easy to understand. The media images and instructions shown in the application are particularly interesting to students. Media images are vividly printed and interesting, arousing students' curiosity. Other than the entire catalog for any media that was displayed was made in language that was clear enough for the students to understand. The steps that should be taken in the use of the MIT app inventor are made in simple, clear language.

6. Ease of applications for good use by students. Applications that are simple and easy for elementary students and students to use. Applications can be installed in student and student android phones so that anytime and anywhere students and students can use them.

\section{Conclusion}

The research aims to develop and develop materials for integrated mathematics studies, local wisdom in north Sumatra, using an MIT App Inventor application for elementary school teachers, the field university faculty of education. The results of validation of the draft materials taught locally integrated mathematics studies in north Sumatra are using an MIT application performed by the validator team made up of the validator team of teachers, princitors and professors of the terrain state university using a previously drawn validation sheet, Point out that the teaching materials and applications that are designed are in good category and are very appropriate for students at the university of medan. The use of local wisdom available in north Sumatra in the form of a game of learning gave the students a different atmosphere that encouraged them to pursue the teaching learning process developed by the teacher. A revision of the materials for integrated mathematics studies in north Sumatra used the MIT application of local wisdom in north Sumatra to fit the application of the validator team to bring the book's quality to a better level so as to get a maximum result when applied in the college process.

\section{References}

[1] Lestari I. Pengembangan bahan ajar berbasis kompetensi. Padang: Akademia Permata; 2013. 
[2] Iskandar W, Sunendar D. Strategi Pembelajaran Bahasa. Bandung: Rosdakarya; 2008.

[3] Opara JA, Oguzor NS. Inquiry instructional method and the school science curriculum. Current res j soc sci. 2011; 3(3):188-198.

[4] Andi P. Panduan kreatif membuat bahan ajar inovatif. Jogjakarta: Diva Press. Rahmat; 2011.

[5] Suparman MA. Desain instruksional modern. Jakarta: Erlangga; 2012. 88, 48.

[6] Hasan I. Analisis Data Penelitian dengan Statistik. Jakarta: Bumi Aksara; 2008. 